\title{
Understanding the Sociological Processes and Mechanisms of School Drop-Out in the Sfax Region of Tunisia: Preliminary Study
}

\author{
Aicha Cherif1, Nizar Ghayaza², Ali Elloumi ${ }^{3}$ \\ ${ }^{1}$ ECUMUS Laboratory, University 9 April, Tunis, Tunisia \\ ${ }^{2}$ ECUMUS Laboratory, University of Sfax, Sfax, Tunisia \\ ${ }^{3}$ TEC Laboratory, University Paris Descartes, Paris, France \\ Email: alielloumi62@gmail.com
}

How to cite this paper: Cherif, A., Ghayaza, N., \& Elloumi, A. (2020). Understanding the Sociological Processes and Mechanisms of School Drop-Out in the Sfax Region of Tunisia: Preliminary Study. Advances in Applied Sociology, 10, 129-156. https://doi.org/10.4236/aasoci.2020.105010

Received: April 29, 2020

Accepted: May 24, 2020

Published: May 27, 2020

Copyright $\odot 2020$ by author(s) and Scientific Research Publishing Inc. This work is licensed under the Creative Commons Attribution International License (CC BY 4.0).

http://creativecommons.org/licenses/by/4.0/

\begin{abstract}
The purpose of this article was to identify the main factors influencing school dropout in Tunisia. With this work we want to draw attention to a social problem that manifests itself with an increasingly strong intensity from year to year in Tunisia, namely school dropout problem, mainly due to deepening poverty (especially in rural areas but not only). In the elaboration of this work we started from processing and interpretation of statistical data provided by the multiple-choice questionnaire. As a result, the causes of school dropout differ from rural and urban space and from region to region. Our analyzes indicate that the probabilities of dropping out are mainly associated with individual behavior, a set of school factors, socioeconomic, family and especially cultural and geographic factors among middle school pupils in the Sfax (Tunisia). Thus, our study tends to understand the mechanisms and sociological processes of dropping out of school. This result indeed confirms the cultural and geographic specificities of Tunisia at this level.
\end{abstract}

\section{Keywords}

School Dropout, Factor of School Dropout, Level of Education, Tunisian Specificities

\section{Introduction}

The education system in Tunisia has not followed social change. We have not witnessed in recent years an educational reform that could contribute to the evolution of this system compared to what is universally required. Indeed, the media are demanding changes in practices and those involved in the education 
sector are questioning their role. Through these many upheavals, the Ministry of National Education points to the school reality in Tunisia and its problem by confirming the number of students who drop out each year $(110,000)$. But what happens to this portion of demotivated young people who think they will leave the school system permanently? What are the causes of this dropout? What are the sources of motivation that lead to persistence in school? How do young people perceive persistence and dropping out of school? Do they have suggestions to make, possible solutions to share?

This study is designed to uncover the different causes of school dropout. As a teacher, I am particularly interested in the social and professional integration of young people who leave our Tunisian schools without a diploma after having spent several years there. I am concerned about a motivation of young people to continue or complete their secondary studies. In 2018-2019, (30\%) of young Tunisians left the school system without a high school diploma in their pocket. Following my research work in bachelor and master, I realized that it would be enriching for my research axis to further develop my knowledge on dropping out of school. We are going to see how this phenomenon is perceived by Tunisian students? What drives some young people to leave school before they even graduate?

The problem of the proposed research is integrated with that of school dropout and even social dropout. In fact, the consequences of exclusion or self-exclusion from school on young people who attempt social and professional integration cannot be ignored. In fact, this integration is compromised by the fact that they find it more difficult to find a job given the less developed skills and the sometimes-inadequate level of literacy to occupy the desired job. Some links have even been established between dropping out of school and crime, consumption of alcohol and drugs (Looker \& Thiessen, 2008). Teachers and parents do not always understand the reasons why pupils leave school and choose a more difficult path. The Tunisian school system certainly does not meet the needs of each student. Some of them succeed in obtaining a diploma while others feel totally incapable of it. To see more clearly, it seems important to study the different causes of school dropout among young Tunisians in order to highlight useful elements to remedy them. Young people, who are at the very heart of the phenomenon, may have a different explanation from that proposed by the writings which deal more with the perception of professionals and practitioners. Young people loudly proclaim that they want society to listen to them and take their needs into consideration. Pupils loudly proclaim that they want society to listen to them and take their needs into consideration. However, few writings and research are interested in the perception that young people have of school organization or even the improvements they would like to make. Pupils are the beneficiaries and the reason to be of our education system. It is outside people who analyze the situation and suggest possible solutions to the problem as they perceive it. So, it seems appropriate to go and check what the young per- 
son has to say about the school system in which he operates. Indeed, the law of public education indicates that:

"Every Tunisian child must attend a school from the first day of the calendar of the school year following that in which he reached the age of six, until the last day of the school year in which he reaches the age of 16 or at the end of which he obtains a diploma issued by the ministry ..." (Tunisian Ministry of Education, 2016).

He has little choice. He must therefore adapt as best he can and want the school to meet his needs. Several studies tackle the phenomenon of school dropout, but the interest of this study lies more in the perception of young people with regard to drop-out and especially the understanding of the sociological mechanisms of this process. The speech of the Minister of National Education in Tunisia (June, 2019) highlighted an alarming record on school dropout. This speech was a trigger. Giving students the opportunity to freely express their perceptions of the Tunisian school system leads me to believe that they are capable of making us understand what helps them to persevere in their studies and what motivates them. It is the perceptions of middle school students in the Sfax region that this study wishes to identify. Young people are the main beneficiaries of the Tunisian school system, therefore, a question of the social and scientific relevance of the research. For several years, the phenomenon of dropping out of school has been growing. Society and stakeholders in the education sector are concerned about the high dropout rate before the end of secondary education. Unfortunately, since school dropout is foremost a process. The problem does not appear overnight among, primary, middle school and secondary pupils. From elementary school, teachers can detect signs indicating that some students are already disinterested. We notice, therefore, a drop in interest with regard to school as well as a disengagement in terms of knowledge construction and in terms of social participation. It is worrying to read that (30\%) of young dropouts say that they do not like school and are dissatisfied with the programs offered to them (Tunisian Ministry of Education, 2017). Motivation, learning and/or behavioral difficulties can lead some young people to become "potential dropouts". Studies indicate that the reason most often cited by young people when they drop out of school is related to school-related reasons, which includes boredom at school, lack of interest in the courses offered, difficulties with school work and problems with teachers (Bushnik, Barr-Telford, \& Buissière, 2002; Gingras, 1995). The problem of school dropout is very broad and seems to affect several countries, mainly the industrialized countries. European countries are concerned that pupils with difficulties leave school without proper qualifications to integrate into the labor market. In fact, the socio-economic integration of these young non-graduates being more difficult, it affects the economic stability of these countries. "In fact, economic stability and education go hand in hand, in that the economic health of a region is dependent on the literacy rate and numeracy of the population" (Boisonneault, Michaud, Côté, Tremblay, \& Allaire, 
2007: p. 6).

Many studies have looked at risk factors for school dropout as a multidimensional phenomenon. We now know that it follows a long process of disengagement from school and that it is preceded by negative school experiences (for example behavioral difficulties and poor academic performance, Christenson \& Thurlow, 2004) and as a phenomenon multidimensional (Fortin, Marcotte, Potvin, Royer, \& Joly, 2006; Blaya, 2010).

Several studies have sought to identify these explanatory factors for dropping out in a cross-sectional manner, that is to say, by studying a few isolated factors. While other studies have focused on studying the factors in an integrated manner (Ensminger \& Slusarcick, 1992; Rumberger, 1995; Stearns, Moller, Blau, \& Potochnick, 2007). The literature review highlighted the following factors: Individual, family, school, cultural, and socio-economic factors. For Rumberger, (1995, 2011), the structural and normative characteristics of schools influence the probability of dropping out as measured by the strongest behavioral predictor of dropping out, namely absenteeism. Motivation, learning and/or behavioral difficulties can lead some young people to become "potential dropouts". Studies indicate that the reason most often cited by young people when they drop out of school is related to school-related reasons, which includes boredom at school, lack of interest in the courses offered, difficulties with school work and problems with teachers (Bushnik, Barr-Telford \& Buissière, 2002; Gingras, 1995).

Potvin et al. (1999) and Blaya (2010) also indicate that dropouts attribute their academic difficulties to the following four reasons: 1) teaching methods and teacher attitudes; 2) their own learning difficulties: lack of concentration and memory, better aptitude for manual work than intellectual work; 3 ) their lack of effort or laziness; and 4) delinquent behaviour that leads them to have only fun. The dissatisfaction of school dropouts is evident in these authors. Jimerson, Egeland, Sroufe and Carlson (2000) put behavioral problems on a pedestal as the best predictor of dropping out of school. For their part, Fortin et al. (2006) emphasized "hidden antisocial behaviours" (as an illustration of theft, lying, barbarism, etc.).

Blaya (2010) and Fortin et al. (2006) note, among other things, that dropping out is not always related to academic difficulties. They mention that dropouts show similar academic results to other students. On the contrary, they differ in their social behavioural models and their perception of academic injustice. The family and economic situation of dropouts is precarious: single-parent families, parents with little schooling and in difficult economic situations.

From our perspective, we opt for the opinion of Janosz (2000), who postulates that the accumulation of negative factors increases the risk of dropping out of school. In fact, it is essential to consider all of the preceding factors but in interaction with each other in order to understand the links between them and to reveal the most "predictive" factors within the factors cited (Galand \& Hospel, 2015; Battin-Pearson et al., 2000). 
In short, the young person leaves school following a combination of personal and family, school and social difficulties. Today, many researchers agree that dropping out of school is a multidimensional phenomenon resulting from a combination of risk factors interacting with each other. Currently, several research projects in the world are already working to reduce the dropout rate by setting up programs which are aimed at young people attending school. It is therefore not surprising to note that, for several research has been carried out to understand the phenomenon of school dropout and to try to identify the main causes. These works have both a quantitative dimension. This study on school dropout in Tunisia could make it possible to draw a parallel between certain results of the work carried out so far. Our objective in this study is to describe and analyze the perceptions of Tunisian students with regard to school dropout and understanding the sociological mechanisms of its process. Following the development of this research issue, two specific questions are raised. The following questions will be at the very heart of the research process and will guide the entire methodology and processing of future data:

- What is the perception of middle school students with regard to dropping out of school?

- What are the sociological mechanisms and processes of this phenomenon?

\section{Methods and Materials}

\subsection{Scope}

This study is part of a quantitative research methodology. The questionnaire used is a general information tool, it includes socio-demographic indicators such as age, sex, social background, civil status, etc. Also, we find the following variables: causes of school dropout, such as family and social, economic, school, personal, cultural etc. In this case, the research data are therefore digital in nature. The choice of a quantitative study is justified by a survey of the perception and understanding of the complex phenomenon of pupil's dropout of themselves. The statistical analysis is based on the relevant details which will make it possible to obtain the contextual information and to describe as faithfully as possible the perceptions of the middle school children regarding dropping out. This questionnaire allows us to understand the mechanisms and processes of school dropout by measuring and describing the different causes perceived by middle school pupils in Sfax (Tunisia). The questionnaire was designed as a self-assessment tool, using colloquial and simple language in the reformulation of the different declarations in a total of 68 elements.

In order to collect the opinion of dropouts on the phenomenon of early school leaving, a questionnaire was used sent to 299 subjects from both social backgrounds of the Sfax region (Rural \& urban) and based on statistical data from the Ministry of Education in Tunisia (2018-2019), a school dropout rate higher than $30 \%$. Through these many upheavals, the Ministry of National Education points to the school reality in Tunisia and its problem by confirming the number 
of students who drop out each year (110,000 pupils). The completed questionnaires were handed over in a classroom and are used for this study. Respondents (53\% male and $47 \%$ female) have an average age of 14.11 years (standard deviation: 5.96).

\subsection{Sampling}

The population to be studied consists of young people attending an educational institution, having at least the age to attend a college and coming from the Sfax and its suburbs. It is the perceptions of this population regarding school dropout that the study attempts to identify. Nearly 299 college students, aged 12 to 15 , participated in this survey, which took place in September and December 2019. These young people work in urban and rural colleges from the Sfax region. Thus, 4 colleges (two in the city center and the other two in the suburbs) are represented. $53 \%$ of the sample is boys and $47 \%$ is girls. Based on the socio-demographic indices of the questionnaire, the cohort of Sfax suburbs is located in a rather popular economic district while those of Sfax-center come from a district of average socioeconomic level (see Table 1).

The sample retained here is intentional, that is to say that it was planned based on a set of criteria (Savoie-Zajc, 2000). It was obtained using the volunteer sample technique which turns out to be a non-probabilistic technique (Beaud, 2003). However, to allow a certain generalization of the remarks collected, it is important to reduce sampling errors. One of the effective techniques for achieving this consists in "reproducing the global population as faithfully as possible, taking into account the known characteristics of the latter" (Beaud, 2003: p. 220). A list of criteria for selecting participants has been previously given to educational institutions. The main elements were:

- $53 \%$ of participants must be boys (high dropout rate in Sfax).

- The representativeness of the levels must be fair.

- Different profiles of young people are requested (young people involved, at risk, hookers, who like school).

Table 1. Characteristics of participants $(n=299)$ according to social space (rural/urban).

\begin{tabular}{ccc}
\hline $\begin{array}{c}\text { Social space } \\
\text { Characteristics }\end{array}$ & $\begin{array}{c}\text { Rural } \\
\text { N = } 149(\mathbf{4 7} \%)\end{array}$ & $\begin{array}{c}\text { Urban } \\
\text { Age }\end{array}$ \\
Boys & 13.99 & 14.23 \\
Girls & $27 \%$ & $26 \%$ \\
Type of residence & $20 \%$ & $27 \%$ \\
7th basic middle school & Popular (29\%), Mixed (51\%), & Popular (25\%), Mixed (45\%), \\
8th basic middle school & Bourgeois (20\%) & Bourgeois (30\%) \\
9th basic middle school & $15 \%$ & $18 \%$ \\
Family composition & $12 \%$ & $10 \%$ \\
\hline
\end{tabular}




\subsection{Measurement}

Most of the measures are based on existing scales, the formulation of which has been adapted to the context of this study. A pre-test was carried out on a sample of pupils in grades $7,8,9$, in Sfax context. In addition to the pre-test, a focus group on the questionnaire was conducted with a group of students with the same characteristics as the target sample. The pupils were generally very receptive and their remarks made it possible to adapt the questionnaire, as well as the handing protocol.

This study is part of a quantitative research methodology. The questionnaire used is a general information tool, it includes socio-demographic indicators such as age, sex, social background, civil status, etc. Also, we find the following variables: causes of school dropout, such as family social, economic, school, and personal etc., In this case, the research data are therefore, of ordinary in nature.

The choice of a quantitative study is justified, considering that the objective is to deepen the understanding of the complex phenomenon of dropping out of school by probing the perceptions of the students themselves. It is a descriptive search. The emphasis is therefore placed here on the relevant details which will make it possible to obtain contextual information making it possible to describe as faithfully as possible the perceptions of college students with regard to dropping out of school. This questionnaire measures and describes the various causes perceived by middle school students in the Sfax region. Its abridged version includes 69 statements distributed equally on seven (7) subscales: 1) educational factor, 2) family factor, 3) social factor 4) economic factor, 5) personal factor, 6) cultural factor, and 7) geographic factor. The answers are of true or false type.

The measuring instrument demonstrates a satisfactory internal consistency Cronbach's alpha varying between 0.72 and 0.89 in this sample (Table 2).

\section{Results}

This chapter presents analysis and interpretation of information collected from the field survey. The results are presented and discussed from different angles, emphasizing the phenomenon of dropping out of school in order to identify the real causes perceived by Sfaxian college pupils.

\subsection{Socio-Demographic Characteristics of the Study Sample}

A total of 299 pupils were investigated in the present study whose demographic characteristics are given in terms of age; siblings, marital status; level of education; type of residence, and employment status. Table 3 shows these indicators.

Table 2. Validity of the construct.

Internal consistency (Cronbach's alpha: 0.89)

Internal consistency the sub-scales the coefficients vary from 0.72 to 0.84

The test-retest reliability of the questionnaire is greater than 0.72 . 
Table 3. Synthetic view of the socio-demographic characteristics of the participants according to social space (rural/urban).

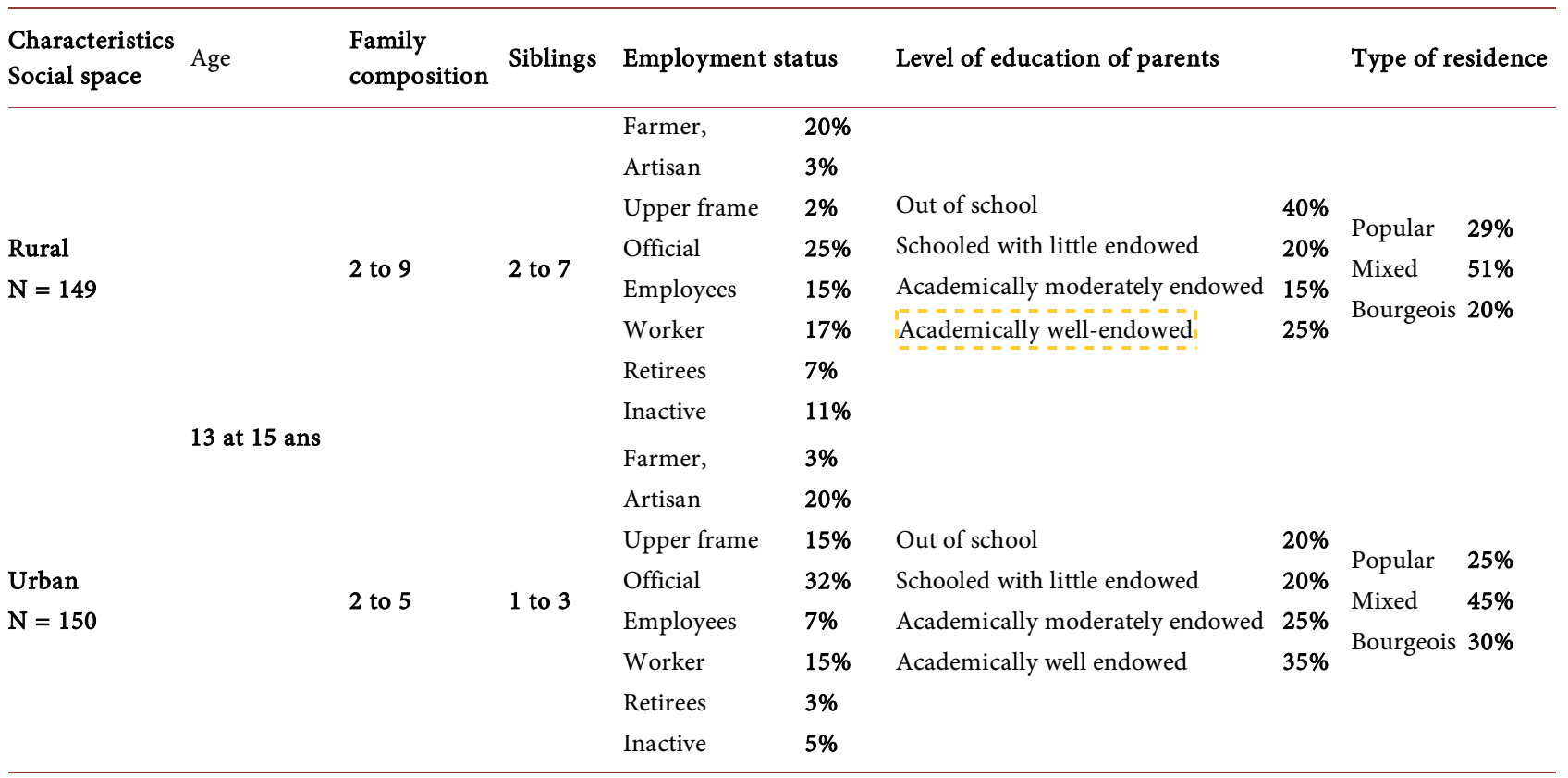

The socio-demographic data provide the elements summarized in Table 1. Of the two hundred and ninety-nine (299) students surveyed in two different environments (Urban \& rural), all are between 12 and 15 years old.

With regard to family composition, the majority of young people in the sample live with their parents (married) and the rest live in a single-parent family, the head of the family being the mother and/or the father. It should be noted that five students now live with their grandparents. In rural areas, the family is made up ( 2 to 7 people), on the other hand, in urban areas, it has ( 2 to 5 people) (see Figure 1).

In the rural area, four cases out of eight, the youngster has too many siblings ( 2 to 7 brothers and sisters), on the other hand, in the urban area, the students have a small brotherhood, it is composed of ( 1 to 3 brothers and sisters) (see Figure 2). Typically, these are the families of senior managers and public servants who have few siblings.

According to our survey, the socio-professional categories of parents are more of a farmer, worker, craftsman, civil servant and intermediary type. More specifically, in rural areas, the rate of children of workers, employees, retirees and inactive (total percentage) is $75 \%$, concerning the children of managers, artisans and farmers, they represent on average $25 \%$ (total percentage). In contrast, in urban areas, the rate of children of employees, workers, retirees, inactive is $30 \%$ (total percentage). The rest of the socio-professional category is represented at $70 \%$ (total percentage). We can thus note that children whose father is a worker (52\% all areas combined) are more likely to drop out than those whose father is a manager (see Figure 3).

Even the level of education of heads of families is very disparate. There are 
considerable differences in this area in the two contexts (Rural, urban). According to the data from our survey, $70 \%$ of the parents of children in our social space are, out of school, little and moderately educated (75\%, total percentage in rural space and $65 \%$, total percentage in urban space), against $30 \%$ of those whose parents are graduates of higher education, i.e. (25\%, total percentage in rural space and 35\%, total percentage in urban space). Could this result tell us about the inability of parents with low education to follow their child's school education (see Figure 4)?

Finally, with the growing social environment and the type of neighborhood of residence (Table 2), the most important result reveals that more than a third of the surveyed population residing in popular areas is $54 \%$ or $(29 \%$ rural area and $25 \%$ urban area) where the local educational offer is of a disadvantaged type. Can this portion tell us about the rate of students who could drop out of school due to the living environment (see Figure 5)?

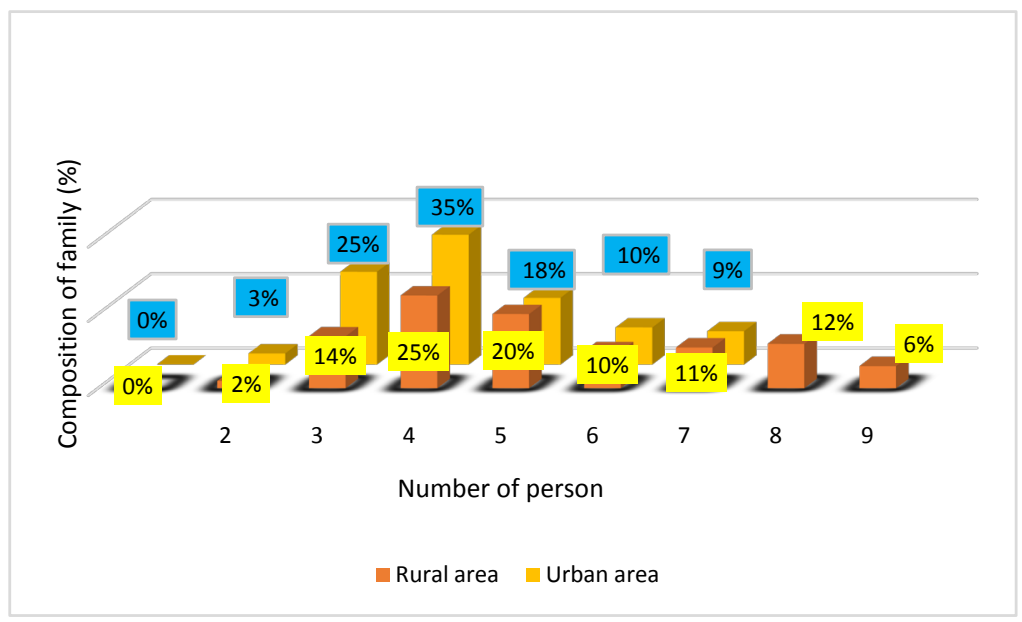

Figure 1. Synthetic view of the family composition data according to social space (rural/urban).

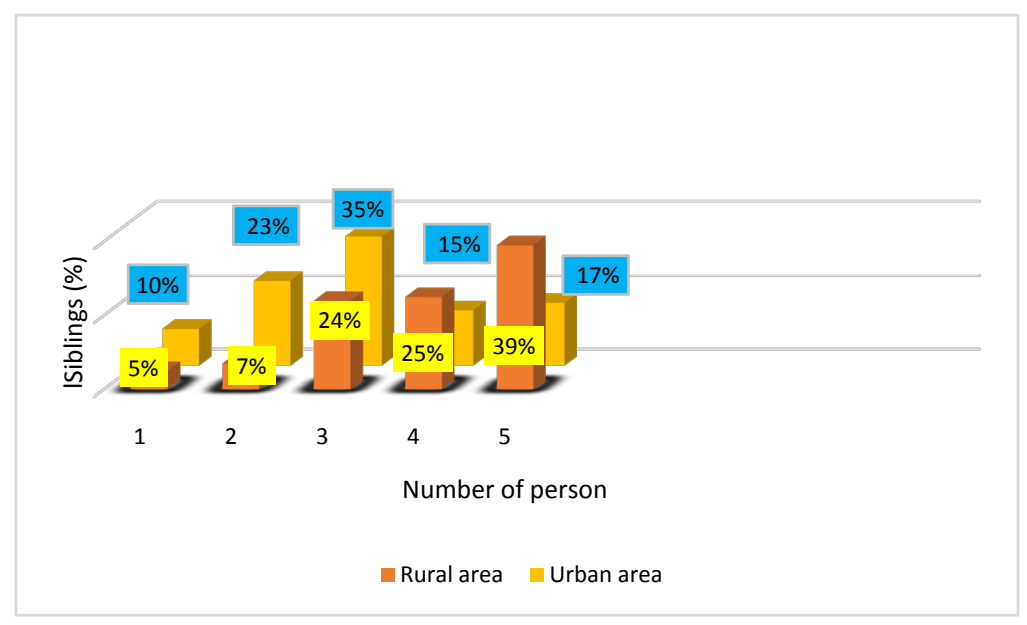

Figure 2. Synthetic view of the siblings data according to social space (ru$\mathrm{ral} / \mathrm{urban})$. 


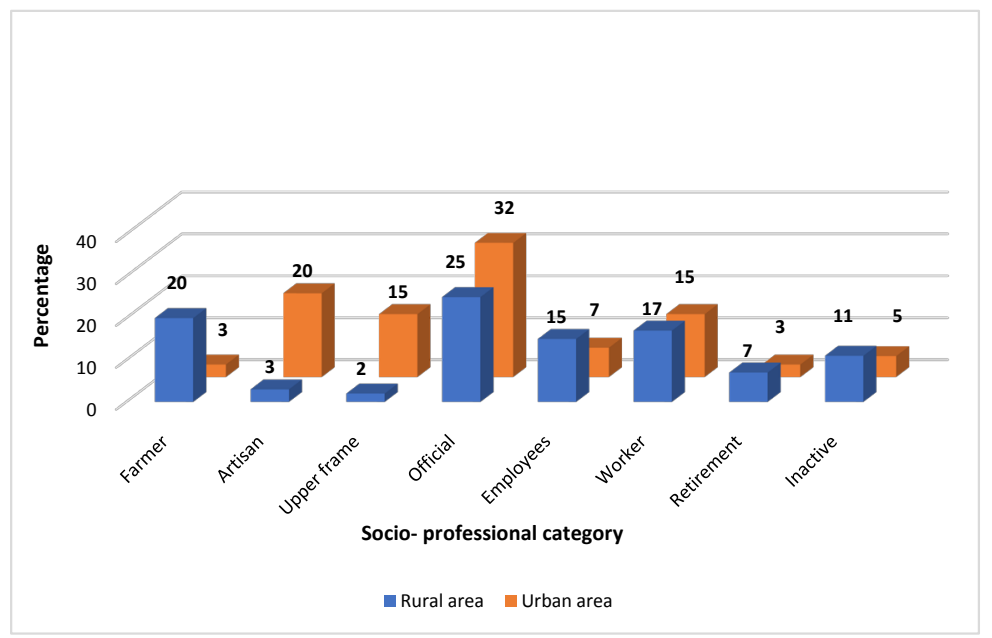

Figure 3. Synthetic view of socio-professional category data according to social space (rural \& urban).

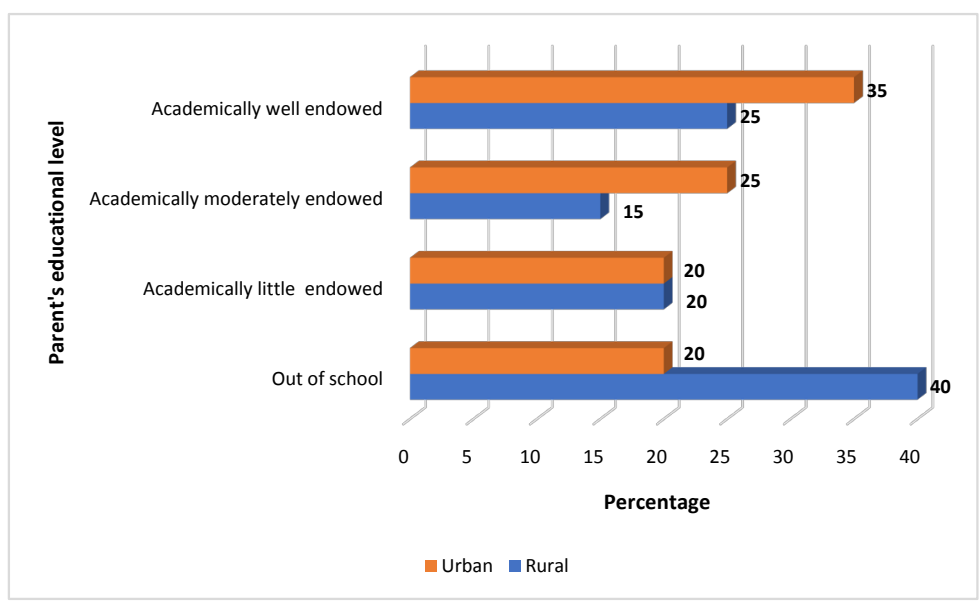

Figure 4. Synthetic view of the parent's educational level data according to social space (rural \& urban).

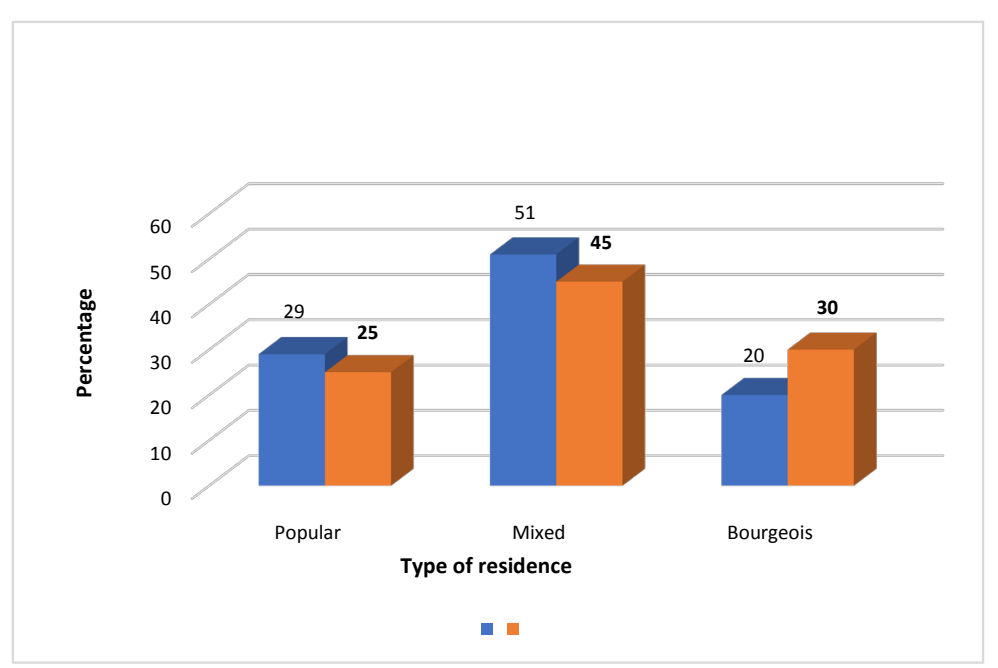

Figure 5. Synthetic view of type of residence data according to social space (rural \& urban). 
Regarding the relationship between living in a bourgeois neighborhood and being educated in a nearby college, this portion represents $25 \%$ or ( $20 \%$ in the rural area and $30 \%$ in the urban area). As you would expect, Sfaxian middle school students are spread across the different districts of the city and the rural area. The rest of the study population (all backgrounds) lives in a mixed neighborhood (27\%). The social environment also affects the context of life (type of residence and neighborhood) and school life (social composition of schools). Again, the inequalities are clear: almost a third of young people living in sensitive urban areas drop out of school. This proportion is twice as large as that recorded elsewhere.

Given the spatial inequality faced with the distribution of the school offer, can it be said that the students derive the same advantage, the same profit as regards inclusion in a neighborhood that brings educational advantages? Do all students benefit from the educational opportunities offered by the neighborhood or do some remain, particularly those of popular origin, disadvantaged despite these opportunities?

Such a result would tend to show that there is indeed an effect of the location of the school offer on family schooling practices, including for working-class families who show a greater propensity to send their child to school in the public sector when there is an offer near their home. Admittedly, the results indicate that indeed all of the students benefit from the educational advantages of their neighborhood of residence. The probability of being educated in a privileged college increases appreciably when the students live in a bourgeois district and this whatever their social category.

These first results clearly show the incidence of socio-demographic characteristics in access to advantageous educational resources. This capital initially seems very strongly linked to social and economic capital. It contributes secondly to inequalities in access to housing and widens the inequality gaps further. Consequently, they are linked to the unequal endowment of the school offer according to the type of district and the unequal capacity of the different social categories to benefit from this advantage. Although it exerts a certain influence on the educational practices of working-class families and the probability for their children of being educated in a privileged establishment, position capital contributes to amplify the inequalities of education between "socio-spatial" groups rather than to reduce them.

We tried to show in this first part of this study the importance of the socio-demographic dimensions concerning the analysis of the factors of school dropout. We still have to corroborate these conclusions using the results of a logistic modeling seeking to measure the relative weight of the different variables analyzed and likely to explain these dropout factors. The following section presents the overall effect of each of the variables used in our analysis. It clearly underlines the major and determining role played by the variables describing socioeconomic and educational characteristics in explaining the different factors of students in the Sfax region. 


\subsection{Factors of School Dropout According to the Perceptions of College Pupils}

The results, of this part, make it possible to group the data of the participants into two main themes. We therefore find a first thematic dealing with the different causes of school dropout and the understanding of the phenomenon of school dropout by college students in the Sfax region. Finally, we conclude by presenting the suggestions and possible solutions provided by the participants in order to promote academic success.

The first theme presented responds directly to the first objective of the research, which is to describe and analyze the perceptions of college students with regard to school dropout. Table 3, presents the distribution of meaning data related to the first theme of this research objective, namely: the perception of the causes of school dropout as well as the understanding of the phenomenon of school dropout among college students.

Above table shows that $52.5 \%$ parents and $62.5 \%$ children do not support that tense environment at home was a cause of dropout. 95\% parents and 100\% children are in favor that illiteracy of parents was a cause of dropout. $72.5 \%$ parents and $85 \%$ children do not favor that family enmity of parents was a cause of their children dropout. $77.5 \%$ parents and $72.5 \%$ children do not support that lack of spouses' understanding was a cause of dropout. 75\% parents and 95\% children are in favor that they considered the education unfruitful that cause dropout. 90\% parents and 95\% children are in support that parents' engagement in earnings was a cause of dropout. $100 \%$ parents and children are in favor that children left schools due to their financial problem. $82.5 \%$ parents considered education as economic burden while $57.5 \%$ children do not think so. $87.5 \%$ parents and $85 \%$ children agreed that engaging children in earning was a cause of dropout. 87.5 parents and $95 \%$ children are in favor that parents' poor economic condition was the cause of children dropout at middle school level in district of Sfax, Tunisia (Table 4).

Table 4. General distribution of data of the dropout factor according to the social areas.

\begin{tabular}{|c|c|c|c|c|c|}
\hline \multirow{2}{*}{$\begin{array}{c}\text { Social area } \\
\text { Factors }\end{array}$} & \multicolumn{2}{|c|}{ Rural } & \multicolumn{2}{|c|}{ Urban } & \multirow{2}{*}{$\begin{array}{c}\text { Total } \\
\mathrm{N}=299 \\
\%\end{array}$} \\
\hline & $\mathrm{N}=149$ & $\%$ & $\mathrm{~N}=150$ & $\%$ & \\
\hline School & 11 & 7.50 & 26 & 17.00 & $37(12.25)$ \\
\hline Personal & 12 & 8.00 & 20 & 13.00 & $32(10.50)$ \\
\hline Social & 30 & 20.00 & 25 & 17.00 & $55(18.50)$ \\
\hline Family & 30 & 20.00 & 34 & 23.00 & $64(21.50)$ \\
\hline Economic & 25 & 17.00 & 23 & 15.00 & $48(16.00)$ \\
\hline Geographical & 15 & 10.00 & 7 & 5.00 & $22(7.50)$ \\
\hline Cultural & 26 & 17.50 & 15 & 10.00 & $41(13.75)$ \\
\hline Total & 149 & $100 \%$ & 150 & $100 \%$ & $100 \%$ \\
\hline
\end{tabular}

Note: the data in the parentheses indicate the total percentage of the dropout factor. 
School dropout is a "complex multidimensional phenomenon resulting from a combination of factors interacting with each other" (Potvin \& Pinard, 2010). It is the culmination of a long process in which each of the parties (teachers, parents, pupils, context ...) seems to have a certain responsibility. Dropping out is therefore complex and there are many factors that can be the cause. In fact, there is no single factor that justifies a dropout situation (Potvin et al., 2006; Blaya, 2010).

In the table above, we have indicators which are all based on the same concept of dropping out of school as an identifiable situation at a given time. They thus allow a quantitative measurement based on the notion of process (Bernard, 2013).

\subsubsection{Common Causes of School Dropout in the Tunisian Context}

The Perception of the causes of school dropout brings together the seven causes, (i.e. $100 \%$ ) of the total responses. Within this table, seven categories make it possible to define the perception of middle school students (rural/urban) as to the causes of school dropout. In order of importance of the results, the causes linked to the orders, that, social injustices, family, economic problems, cultural traditions, and the geographic context are the real causes of dropout of school (all environments combined), followed by institutional problems and finally the causes which relate to the personal aspect.

As indicated in Table 3, the children of the two social spaces (rural and urban) affirm that family problems (21.50\%), social injustices (18.50\%), economic problems $(\underline{16 \%)}$ and cultural traditions $(13,75 \%)$ are the most common causes of school dropout followed by institutional problems (12.25), individual disorders (10.50\%) and geographic context (7.50\%) Except for the major common causes, the children of rural space and urban areas differed in their opinion about the causes of the dropout. The pupils of rural space mentioned that the cultural traditions (17.50\%) and the geographic context (10.00\%) as second causes of school dropout even before school problems (7.50\%) and individual disorders $(8.00 \%)$. However, the children of urban areas mentioned that school problems $(17.00 \%)$, social injustices $(17.00 \%)$ and economic problems $(15.00 \%)$ for their dropout.

Consequently, we note that the classification of the causes of school dropout differ according to social space. In this first analysis, we insist on the emergence of two very relevant school dropout factors (cultural obstacles and geographic disparities) which were never cited in Western and Anglo-Saxon scientific work. So, we can affirm that these are factors of school dropout specifically African and which characterize the social situation in emerging countries. It should be noted that the importance attributed by Tunisian students to the causes of school dropout linked to these factors does not in any way support the work that defines school dropout as the erosion of the relationship between young people and school until that the latter is no longer strange for young people (Bloch \& Gerde, 2004; Favresse \& Piette, 2004). As a result, the causes of school dropout differ from one developed country to another one. This result indeed confirms the socioeconomic and cultural specificity of Tunisia at this level. 
We treat in next part (Table 5), the result of the various detailed causes of the school dropout and especially the most influenced by the pupils who evolve in two different social spaces (Rural \& urban).

\subsubsection{Common School Causes in Rural and Urban Areas (See Table 4)}

Analysis of the statistical data reveals that the most influential causes of schooling by students in rural and urban areas is the general functioning of the school system is even problematic (12.50\%). By way of illustration, we cite the academic commitment at the level of the student but also of the teacher, the school climate, the clarity of the school rules, labeling, orientation, school programs, etc. are all variables to be considered in the Tunisian context (all social spaces combined). Our results join in this sense the work of Blaya (2010), which stipulate that the school climate in general and the labeling phenomenon are central. By labeling, we are either a good or a bad student. This is a classification that the youngster will internalize. When a student experiences difficulty at school, the institution will tend to "naturalize", "pathologize" and "outsource" these (Thibert, 2013). The young Tunisian thus thinks that his place is effectively not in the school system since the latter does not want him.

Failure in exams, punishment and insults in school, dissatisfaction with school, academic learning too abstract, unequal opportunity and inadequate school climate are all phenomena that young people have to face (Chenu \& Blondin, 2013). Consequently, Tunisian students in difficult circumstances at school tend to group themselves in a subculture of opposition to the system in a process reacting to the stigma or exclusion they suffer. This victimization can also lead to dissatisfaction with school and therefore "increase the feeling of exclusion from school" (Blaya, 2010).

Furthermore, according to the perceptions of Tunisian student, the harassment situations, bad relationships between student and teacher are all causes that can have a strong impact on the children. The organization of the class, the support provided by the teacher, the way in which the rules are dictated and perceived, etc. can bring a Tunisian student a feeling of "insecurity" and a "negative vision of the establishment" (Blaya, 2010). If the pupil doesn't feel right in his school, he will tend to skip class.

The orientation undergone (especially the vocational streams) is also an important cause playing on the school dropout of students from a disadvantaged social background. Some Tunisian students perceive cognitively inaccessible what is asked of them in class methodologically which prompt them quickly to feel excluded from school. This result corroborates the progress of a PISA study from 2009 which shows that the grouping of young people from a disadvantaged social category increases the risk of dropping out (Thibert, 2013).

It is obvious that school's infrastructure in the urban middle school was found better than that of rural with respect to availability and adequacy of facilities such as (school building, classroom and toilet, drinking water, playground and instructional materials). These facilities were not available at all in majority of the rural schools. 
Table 5. Distribution of data on the most influential causes of school dropout by urban and rural areas.

\begin{tabular}{|c|c|c|c|c|c|c|}
\hline \multirow{3}{*}{$\begin{array}{l}\text { Influential causes of dropout } \\
\text { Causes in detail }\end{array}$} & \multicolumn{6}{|c|}{ School's areas } \\
\hline & \multicolumn{2}{|c|}{ Rural $(n=149)$} & \multicolumn{2}{|c|}{ Urban $(n=150)$} & \multicolumn{2}{|c|}{ Total $(\mathrm{n}=299)$} \\
\hline & Number & Percent & Number & Percent & Number & Percent \\
\hline School causes & 11 & $(7.50)$ & 26 & $(17.00)$ & 37 & $(12.50)$ \\
\hline $\begin{array}{l}\text { - Failure in exams (no cognitive presence in class, no value given to education, } \\
\text { evaluation) }\end{array}$ & 2 & 1.34 & 3 & 2.00 & 5 & 1.67 \\
\hline - Punishment and insults in school & 1 & 0.67 & 2 & 1.33 & 3 & 1.00 \\
\hline $\begin{array}{l}\text { - Dissatisfaction with school, (difficulty and not interested in study, bad } \\
\text { relationship with teacher, bad infrastructure) }\end{array}$ & 1 & 0.67 & 2 & 1.33 & 3 & 1.00 \\
\hline $\begin{array}{l}\text { - Academic learning too abstract (little relevant, far from real life, seems to } \\
\text { miss the concerns of adolescents) }\end{array}$ & 2 & 1.34 & 3 & 2.00 & 5 & 1.67 \\
\hline - Inability to buy stationery and books & 1 & 1.34 & 2 & 1.33 & 3 & 1.00 \\
\hline - Unequal opportunity (weak academic aspirations) & 1 & 1.34 & 2 & 1.33 & 3 & 1.00 \\
\hline - Inadequate school climate & 3 & 2.01 & 3 & 2.00 & 6 & 2.00 \\
\hline Family's causes & 30 & $(20.00)$ & 34 & $(23.00)$ & 64 & $(21.50)$ \\
\hline $\begin{array}{l}\text { - Parental support (parent's illiteracy, household chores, looking after the } \\
\text { younger siblings, parents' prohibition to go to school) }\end{array}$ & 8 & 5.36 & 6 & 4.00 & 14 & 4.68 \\
\hline - Lack of family organization (helping family, large number of children) & 7 & 4.69 & 10 & 6.66 & 17 & 5.68 \\
\hline $\begin{array}{l}\text { - Instability in family (deteriorated parent-adolescent relationship, } \\
\text { authoritarian parenting style, difficult family climate life) }\end{array}$ & 6 & 4.02 & 10 & 6.66 & 16 & 5.35 \\
\hline - Low cultural and economic capital & 9 & 6.04 & 8 & 5.33 & 17 & 5.68 \\
\hline Social causes & 30 & $(20.00)$ & 25 & $(17.00)$ & 55 & $(18.50)$ \\
\hline $\begin{array}{l}\text { - Negative school interactions (gender discrimination in school, humiliation } \\
\text { by friends in school) }\end{array}$ & 6 & 4.02 & 5 & 3.33 & 11 & 3.67 \\
\hline - Regional disparities & 6 & 4.02 & 5 & 3.33 & 11 & 3.67 \\
\hline - Problematic behaviors (alcoholism, drug addiction, theft, vandalism) & 6 & 4.02 & 5 & 3.33 & 11 & 3.67 \\
\hline - Persistence of social inequality & 6 & 4.02 & 5 & 3.33 & 11 & 3.67 \\
\hline - Social vulnerability (labeling, gaps in social skills) & 6 & 4.02 & 5 & 3.33 & 11 & 3.67 \\
\hline Economic causes & 25 & $(17.00)$ & 23 & $(15.00)$ & 48 & $(16.00)$ \\
\hline $\begin{array}{l}\text { - Economic insecurity and scarcity (financial constraints, professional } \\
\text { instability of parents) }\end{array}$ & 5 & 3.35 & 7 & 4.66 & 12 & 4.01 \\
\hline - Child labor (agricultural work, engagement in seasonal job and in child labor) & 5 & 3.35 & 5 & 3.33 & 10 & 3.34 \\
\hline - Go for illegal immigration & 5 & 3.35 & 5 & 3.33 & 10 & 3.34 \\
\hline - Go for parallel trade & 5 & 3.35 & 2 & 1.33 & 7 & 2.34 \\
\hline - Rural exodus & 5 & 3.35 & 4 & 2.66 & 9 & 3.01 \\
\hline Personal causes & 12 & $(8.00)$ & 20 & $(13.00)$ & 32 & $(10.50)$ \\
\hline - Low self-esteem (negative school climate, little academic commitment) & 3 & 2.01 & 5 & 3.33 & 8 & 2.67 \\
\hline - Psychological fragility (depression, dramatization, isolation) & 3 & 2.01 & 5 & 3.33 & 8 & 2.67 \\
\hline - Behavior trouble (absenteeism academic difficulties, conflicted relationships) & 3 & 2.01 & 5 & 3.33 & 8 & 2.67 \\
\hline - Cognitive deficit (lack of motivation, low concentration and attention) & 3 & 2.01 & 5 & 3.33 & 8 & 2.67 \\
\hline Cultural causes & 26 & $(17.50)$ & 15 & $(10.00)$ & 41 & $(13.75)$ \\
\hline - Little incentives for girls (early marriage for girls) & 6 & 4.02 & 2 & 1.33 & 8 & 2.67 \\
\hline - Socio-cultural inequality in terms of academic success & 5 & 3.35 & 4 & 2.66 & 9 & 3.01 \\
\hline - School culture competes with media cultures & 5 & 3.35 & 3 & 2.66 & 8 & 2.67 \\
\hline - Inconsistency of family culture and school culture & 5 & 3.35 & 3 & 2.66 & 8 & 2.67 \\
\hline - Traditional customs, beliefs and practices & 5 & 3.35 & 3 & 2.66 & 8 & 2.67 \\
\hline Geographic causes & 15 & $(10.00)$ & 7 & $(5.00)$ & 22 & $(7.50)$ \\
\hline - Distance (school far from home, lack of public transportation and facilities) & 6 & 4.02 & 1 & 6.66 & 7 & 2.34 \\
\hline - Harassment from school/house & 3 & 2.01 & 6 & 4.00 & 9 & 3.01 \\
\hline $\begin{array}{l}\text { - Harsh weather conditions (intense rain, river, mountain forest, presence of } \\
\text { wild animals) }\end{array}$ & 3 & 2.01 & 0 & 0.00 & 3 & 1.00 \\
\hline - Regional physical disparities & 3 & 2.01 & 0 & 0.00 & 3 & 1.00 \\
\hline
\end{tabular}

Note: the data in the parentheses indicate the total percentage of the dropout factor. 


\subsubsection{Common Social Causes in Rural and Urban Areas (See Table 4)}

The result reveals that the most influential causes of school dropout by rural and urban space is social related causes (18.50\%) include, regional disparities (3.67\%); social status, negative school interactions (3.67\%), gender discrimination, child abuse, humiliation by friends ..., deviant behaviors (3.67\%); alcoholism, drug addiction, theft, vandalism, and persistence of social inequality (3.67\%). The interaction of these variables results might likely push the pupil leave the school because of the numerous frustrations experienced in the social context.

The above results indicating that children who drop out of school most often come from poor family background and live in poor neighborhoods far from schools.

The analysis indicated that adolescents from middle and bourgeois social status backgrounds (rural and urban families) were more likely to stay in school than those from the lower social status backgrounds (urban and rural families). We found that at the middle school levels, females from rural area were significantly more likely to dropout than males, either to help the large family or for an early marriage.

Results indicate that the probability of a child dropping out from middle school reduces as one moves from rural to urban areas. This could perhaps explain by the variety of social facilities for going to school in the urban area than in the rural space. Pupils traveling long distances to school are more likely to drop out of school. Whereas distance was found to be insignificant in influencing dropout for urban households, it is generally significant in rural areas except for girls.

Our results go in the same scientific direction of Pierre-Yves Bernard (2017) in his chapter on the social question and the School question where he stipulates that it is in the social/school opposition that resides the main part of the political debate on school dropouts. This opposition is based on the distinction between two orders of phenomena. In the first sense, everything that refers to the socio-economic context experienced by dropouts, including the family educational environment in which they were raised: the social environment, the residential area, the economic situation of the employment area, the available and accessible training offer, etc. On the other sense, everything related to the context of schooling: school experiences, characteristics of establishments, teaching practices, etc. This distinction can be interpreted from a scientific point of view but also in political terms. In terms of scientific approaches, these two orders of phenomena refer, at least in Tunisia, to two successive paradigms of analyzes of educational inequalities. While the theories of reproduction put forward the determinations of the social environment in the school world, the interactionist and constructivist concepts led research to look more at what was happening in the "black box" of the class and of the relationships between teachers and students ... 


\subsubsection{Common Family Causes in Rural and Urban Areas (See Table 4)}

Family factors as the reason for dropping out of school account for almost (21.50\%) of the results relating to the first theme. The lack of support from the family (4.68\%); parent's illiteracy, household chores, looking after the younger siblings, parents' prohibition to go to school, lack of family organization (5.68\%): helping family, large number of children, instability in family (5.35\%): deteriorated parent-adolescent relationship, authoritarian parenting style, difficult family climate life and low cultural and economic capital (5.68\%) is grouped in Table 3, which presents data related to each of the responses from the "Family causes of school dropout". The results show that children do not support that tense environment at home is a cause of dropout and they are in favor that illiteracy of parents is another one. In the other side children are in favor that they left schools due to their financial problem and they agreed that engaging in seasonal job is a cause of dropout, accordingly to the parents' poor economic condition. According to the results obtained, the lack of support from parents is described in different forms. For some, the fact of not being respected in the choice, they make is very demotivating. Young people often mention the need to be encouraged and supported. Some go further by mentioning that they are aware of their shortcomings and difficulties and add that parental punishment or moralizing speech are useless and do not motivate them. For others, it is the pressure from the family and the comparisons made by the parents that undermine their academic motivation.

It is important to make a link with the scientific writings which confirm that family factors are regularly associated with dropping out of school (Rousseau, Tétreault, \& Vézina, 2006; Bushnik, 2003; Blaya, 2010). Difficulties in parenting skills as well as inappropriate practices adopted by parents often explain gaps at the family level (Dubuc, 2003). When school difficulties are added to a fragile family situation, the risk of dropping out of school increases (Bautier, 2006).

\subsubsection{Common Economic Causes in Rural and Urban Areas (See Table 4)}

The above table summarizes the most influential causes of school dropouts as perceived by the key respondents (rural an urban space). It is clear from their perception that there are some common causes of dropout that stand out and over others. In a smaller proportion, the economic difficulties experienced by middle school students complete the family causes mentioned by the students. The most influential causes that are commonly perceived by children are, therefore, related to poor economic problems of the parents $(16.00 \%)$ as being a cause of demotivating and school dropout (rural and urban space). The economic insecurity and scarcity (4.01\%): financial constraints, professional instability of parents, higher costs of studies and the financial needs, Child labor (3.34\%): agricultural work (engagement in seasonal job and in child labor), thinking about illegal immigration (3.34\%), work in parallel trade (2.34) and rural exodus $(3.01 \%)$ are the relevant elements found in the responses of college students that explain their causes of school dropout. 
School dropout is also an outcome of a host of economic causes in both social space (Rural and urban) that have a telling effect on the retention of children in the middle school.

Scientific studies (De Witte et al., 2013; Rumberger, 2011; European Commission, 2014; Mihalache, 2011), showed that poverty and unemployment in the rural space contribute to an increase in migrations in search of jobs. But also, to hiring children in seasonal or family jobs which drag them away from school. Moreover, our data reveal that the choice of specific vocational training within vocational schools is often out of sync with shortages in the job market.

\subsubsection{Common Personal Causes in Rural and Urban Areas (See Table 4)}

Personal problems are elements that occupy a large proportion of respondents in connection with this category. Indeed, this sub-scale represents more than $10.00 \%$ of the responses associated with the causes of school dropout in both space (rural and urban). Young people at risk of dropout experience personal difficulties such as a low self-esteem (2.67\%: negative school climate, little academic commitment), psychological fragility (2.67\%: depression, dramatization, isolation), behavior trouble (2.67\%: absenteeism academic difficulties, conflicted relationships; learning difficulties, lack of social skills, behavioral difficulties and depression) cognitive deficit (2.67\%: lack of motivation, low concentration and attention).

Personal variables play a large part in the school dropout process, particularly with regard to problems of depression and problems of social withdrawal, problems of attention, aggressive and delinquent behavior (Fortin et al., 2006). The school sometimes allows risk factors to settle in, which, if we do not intervene sometimes precipitate the act. These risks factors are: academic difficulties, truancy, lack of school engagement, isolation of the young person, a negative or even violent school climate, and difficult/conflicted relationships between young people or between young people and adults.

As confirmed by Blaya (2010), school dropout has not always been considered associated with deviant or delinquent behavior, especially during periods of full employment. However, the perception and representations of school dropout have changed with the evolution of the labor market. The role assigned to school and they are often associated with other disorders such as the use of drugs, alcohol, tobacco, going out at night, violent behavior and major depressive signs. Scientific studies have shown a strong correlation between absenteeism and deviance, but no study has succeeded in identifying whether school dropout is the cause or the consequence of delinquent behavior. However, it appears that the absence of the school provides free time which can be conducive to delinquent acts. The explanation of this delinquency case lies in problems of rebellion against the parents, in the disappointments due to a chaotic education, and in the psychological fragility. Young people at risk of dropping out are more aggressive and adopt more delinquent behavior and disruptive attitudes in the school environment; they are thus more easily identifiable by teachers. Some 
young people reject responsibility for the problems encountered at school, and adopt aggressive behavior against the school and its representatives, thus contributing to a significant deterioration of the school and classroom (CEREQ, 2005; Fortin \& Picard, 1999; Blaya, 2010).

\subsubsection{Common Cultural Causes in Rural and Urban Areas (See Table 4)}

In our study, the results of the survey of 299 college students in two different areas (rural \& urban) in the Sfax region, reveal that the cultural causes of school dropout are so important (13.75\%). The pupils also say to themselves and especially the girls that the radical customs, beliefs and practices $(2.67 \%)$, are the real obstacle of our academic motivation. Girls from both social spaces (rural \& urban) say that they school dropout, because of little incentives for girls (2.67\%: early marriage for girls). $2.67 \%$ of children confirm the existence of a socio-cultural inequality in terms of academic success. School culture competes with media cultures was chosen by $2.67 \%$ of the respondents. Finally, (2.67\%) of middle school students insist on the inconsistency of family culture and school culture. One hypothesis that could explain these results could be that students are torn between family culture and school culture. This gap between the two pushes them to drop out. The role of family culture in the transmission of values and in the promotion of school is therefore to be taken into account. This result shows a significant variation in the influence of cultural causes according to students in social spaces. As has been clarified in the literature, the concept of cultural dropout is associated with the phenomenon of school dropout. This concept takes on a negative value, and can thus contribute to the stigmatization of students qualified as cultural dropouts. Does the literature on the school choice process support such a concept?

Several studies note the remarkable influence of culture on students' school dropout (Gyonos, 2011; Bosetti, 2004; Dalley \& Saint-Onge, 2008; English, 2009). However, researchers have different definitions of culture. Bosetti (2004) states that the common values and beliefs between families and school constitute one of the most determining factors of school motivation. According to this researcher, culture is relative to all of the parents' values. In the same vein, English (2009) is inspired by Bourdieu and the concept of cultural capital. This researcher emphasizes the importance of developing cultural capital in schools. She specifies that the fact that the school promotes the "right" (p. 90) cultural capital in relation to the different values of the family is a factor considered a priority in the child's educational path. Australian schools recognize this reality and implement programs specializing in arts, music and certain sports to promote the idea that their students will have a better school integration. Bulman (2004), for his part, considers that "culture must be seen as the fabric which enables each family to give meaning to education". He specifies that one cannot suppose that culture is only the ethnicity, the sex, the social class or the religion of a person, but that it is rather the "tool kit", with which it interacts in his daily life. Bulman (2004) maintains that these cultural tools refer to emotional and in- 
trinsic motivations that come into play during the school process. The socio-cultural aspect of school dropout is therefore present in several different ways depending on the student's social context. The data collected in our survey seem to corroborate these findings.

\subsubsection{Common Geographic Causes in Rural and Urban Areas (See Table 4)}

The analysis of the results of the geographic dimension as a dropout factor in two different spaces (rural \& urban) represents a portion of (7.50\%). It can be understood in two somewhat different ways. In the narrow sense, it will be understood as the unequal proximity of families to educational establishments in the two spaces (2.34\%: distance, school far from home, lack of public transportation and facilities), Harassment from school/house (3.01\%) this inequality can be geographic, social or cultural. In the broad sense, access to school is a possibility to learn but harsh weather conditions are often an obstacle to reach school, according to the students of the two spaces (1\%: intense rain, river, mountain forest, presence of wild animals). Consequently, regional geographic disparities (1\%) mark the distortions and draw unequal regional groups. The large geographic disparities revealed by these rates are now very much reduced. However, the children's educational difficulties have not been resolved: judging by the results of the assessments made in primary school, their interregional disparities do not seem to have been resolved. Premature school leaving in rural areas gives a first idea. According to the ministerial report for 2019, it is estimated that 110,000 young people leave the education system without qualifications. However, the inequality of opportunity to access a high level of education fairly closely reflects the social inequalities of Tunisian society. These distortions between the regional origins of rural middle school students and those of pupils of urban space become more marked as one advances in studies. Consequently, our results seem close to scientific writings (MEN DEP, 1993b; Herin, 1990, 1993), which stipulate that access to school is essentially linked to the economic and socio-cultural capital of families of origin. These disparities draw regional groups where the prospects of young people for having a qualification are unequaled. The current configurations of these disparities refer to the geography of the baccalaureate degrees obtained and to the difference observed between students in rural and urban areas. Especially in Sfax-center, the students have the chance to obtain the baccalaureate and pursue higher education, on the other hand, it is not easy to access it for the rural students. Inequalities persist from one region to another. This is further proof that the reforms of the Tunisian education system remain powerless to reduce the geographic inequalities of access to reference schools. Knowing that these geographic inequalities are rooted in the economic, social and cultural realities of regional territories inside the country. These geographic inequalities reflect the differences in the composition of regional populations.

Insofar as the geographic configurations which appear in the frequencies of 
school leavers without qualification, we emit another hypothesis which stipulates that the interpretation of school geographic disparities is to be sought in the diversities of the social structures of the national territory seems most plausible. This hypothesis raises the question of the disadvantage of the countryside compared to the cities with regard to access to reference schools in Tunisia. Rural youth are not as likely to pursue and complete long secondary education as urban youth. Without ignoring the role of the remoteness of the school, the additional costs and the personal difficulties that it represents for a number of young rural people. It would be risky to claim that it is the geographic distance of the young people from establishments would be the essential cause of the training disadvantages of many rural youths.

\subsection{Understanding the Phenomenon of School Dropout}

Middle school students in the Sfax region are very aware of the causes and consequences of dropping out of school. They easily identify what motivates and demotivates them. However, a certain proportion of these young people drop out anyway. It would be interesting to see how they update, in action, the elements they mention in their responses?

The theme "Understanding young people of school dropout" is the result of grouping together some open questions which represent 3\% of the participants' total responses. In this theme, which brings together the perceptions of middle school students in the Sfax region with regard to the phenomenon of dropping out of school, two aspects are addressed. It is first a question of the phenomenon itself and then of the dropouts present in the entourage of the participants.

First of all, dropping out of school does not seem to be a subject spontaneously raised between friends according to the participants who express themselves on the phenomenon. Participants also believe that young people who drop out are intelligent, but that the school does not recognize their intelligence. According to them, the phenomenon is very present and no one is really immune to demotivating and dropping out. Young people also see a link between family values and leaving school. In some cases, it is a sibling while in others, it is a question of friends or acquaintances. It is nevertheless surprising that none of the participants mentioned the complexity of the phenomenon of dropping out of school. Indeed, the authors agree that school dropout is the result of a combination of several factors over a more or less long period of time (Janosz, 2000; Blaya, 2010; Potvin, Fortin, Marcotte, Royer, \& Deslandes, 2004).

The school and its organization are often distinguished by young people. On the teachers' side, the students would like to know their perception of the phenomenon. They would also like the school administrators to put in place the necessary educational and infrastructural conditions which would encourage their retention.

To conclude, it seems important to study more specifically the possible interventions related to vocational development among young people in college. 
Young people express the need for more guidance and information, but they also approach self-knowledge as an element of personal and professional development. With the disappearance of certain courses more focused on personal development and career counseling (e.g. personal and social training, career choice education) and the addition of new courses that do not appear until later in secondary education, the school has not created a loss of meaning in our young people.

School dropout, often, manifests itself in unusual behaviors. Indeed, the child manifests an aggressiveness which requires educational assistance. This failure is also characterized by overt opposition. Then, the anxiety of the note is also a warning sign of a risk of dropping out. This anxiety is usually the result of strong family pressure. Fear of failure is also caused by their inability to cope with failure. Then, neglect of the teacher's orders is a symptom of dropping out. This behavior is similar to the behavior of a child's king who refuses to comply with the requirements of his superior. This attitude may be due to fear of his ability to respond. In addition, academic failure is manifested by a total lack of motivation and unsatisfactory results. Finally, the student finds it difficult to organize and manage his work at home.

\section{General Discussion}

Previous research has sought to examine the impact of a multitude of variables on school dropout, including the effect of student's personal, family, school and social factors, including academic achievement, student behavior or social origin for example. While some have focused on the study of disparities by gender or ethnicity, none of our knowledge has grasped the disparities related to cultural and geographic causes. The purpose of this study was to understand the mechanisms and processes of school dropout in the Sfax region according to the characteristics and types of students.

First, analysis of statistical data reveals that the general functioning of the school system is problematic (12.50\%). This result corroborates the conclusions of previous research identifying institutional problems as associated with dropping out of school (Blaya, 2010; Fortin et al., 2006; Potvin et al. 2006).

In a second step, we highlighted the impact of the social factor on the probability of students' school dropout. The results of these analyses show that the most influential causes of school dropout by rural and urban areas is social causes (18.50\%). Similar results had already been reported in the research literature. Indeed, our results, like those of the theoretical model of Fortin et al. (2006) and as the study by Janosz et al. (1997) show that school dropouts for middle school students are a combination of social causes. These results suggest rather that it is necessary to intervene according to the social characteristics of the pupils, independently of the social space. We nevertheless observe some differences according to gender among the pupils in the two contexts (rural \& urban). The influence of the neighborhood social environment on schooling practices, al- 
though less discriminating than that of the school environment, also plays an important role.

Otherwise, the results reveal that the first reason for school dropout by pupils in rural and urban areas is preponderant in family causes $(21.50 \%)$. These results corroborate previous studies which stipulate that family factors are regularly associated with school dropout of (Janosz, 2000; Potvin et al., 1999; Blaya, 2010). Difficulties in parenting skills as well as inappropriate practices adopted by parents often explain gaps at the family level (Dubuc, 2003). When school difficulties are added to a fragile family situation, the risk of school dropout increases (Bautier, 2006).

In addition, the survey reveals that the most influential causes that are commonly perceived by children are the poor economic problems of the family (16.00\%). School dropout is also an outcome of a host of economic causes in both social space (Rural and urban) that have a telling effect on the retention of children in the middle school.

Scientific studies (De Witte et al., 2013; Rumberger, 2011; European Commission, 2014; Kovač-Cerović et al., 2016), showed that poverty and unemployment in the rural space contribute to an increase illegal migration. But, also to hiring children in seasonal or family jobs which drag them away from school. Moreover, our data reveal that the choice of specific vocational training within vocational schools is often out of sync with shortages in the job market.

Personal problems are elements that occupy a large proportion of respondents in connection with this category. Indeed, this sub-scale represents more than $10.00 \%$ of the responses associated with the causes of school dropout in both space (rural and urban). The personal problems affecting student motivation, addressed by the participants, are varied. However, drug use is the main reason for dropping out of school. Health problems and harassment on the part of some students are also among the personal problems targeted as being likely to affect academic motivation. It is important to make a link with the scientific writings which indicate to us that the gestures or words of depreciation on the part of the teachers have an important impact on the motivation of the student. Indeed, these data's are often perceived by the young person as a direct attack on his person and not as an action directed with a view to correcting undesirable behavior. These teachers' attitudes therefore directly influence the student's self-esteem (Truong, 2006). The classroom and school climate are considered a school factors associated with dropping out (Dubuc, 2003; Potvin, 2005; Blaya, 2010).

The results of the survey of 299 college students in two different areas (rural \& urban) in the Sfax region, reveal that the cultural causes of school dropout are so important (13.75\%). The role of family culture in the transmission of values and in the promotion of school is therefore, to be taken into account. These data show a significant variation in the influence of cultural causes according to students in social spaces. As has been clarified in the literature, the concept of cul- 
tural dropout is associated with the phenomenon of school dropout (English, 2009), this concept takes on a negative value, and can thus contribute to the stigmatization of students qualified as cultural dropouts. According to this researcher, culture is relative to all of the parents' values. In the same vein, English (2009) is inspired by Bourdieu and the concept of cultural capital. This researcher emphasizes the importance of developing cultural capital in schools. Bulman (2004) maintains that these cultural tools refer to emotional and intrinsic motivations that come into play during the school process.

Finally, the analysis of the results of the geographic dimension as a dropout factor in two different spaces (rural \& urban) represents a portion of (7.50\%). The large geographic disparities revealed by these rates are now very much reduced. Premature school leaving in rural area gives a first idea. According to the ministerial report for 2019, it is estimated that 110,000 young people leave the education system without qualifications. However, the inequality of opportunity to access a high level of education fairly closely reflects the social inequalities of Tunisian society. These social inequalities between rural and urban middle school students become more marked as we advance in the school curriculum. Consequently, our results seem close to scientific writings (MEN DEP, 1993a; Herin, 1990, 1993), which stipulate that access to school is essentially linked to the economic and socio-cultural capital of the families of origin. These disparities draw regional groups where the prospects of young people for having a qualification are uneven. The current physiognomy of these disparities refers to the geography of the baccalaureate diplomas obtained and to the difference observed between students in rural and urban areas. By way of illustration, the chance of going to university for a student from the center is better than that for a student from the rural area. This equal opportunity between the Tunisian regions still persists. Without ignoring the role of the remoteness of the school, the additional costs and the personal difficulties that it represents for a number of young rural people, it would be risky to claim that it is the geographic distance of the young people from establishments would be the essential cause of the training disadvantages of many rural youth.

Certainly, the results of this research provide a relevant source of information and help in a better understanding of school dropout. But they are not exhaustive. The specificity of this study lies in its contribution to other factors which were not taken into consideration in previous work, such as cultural and geographical factors which represent fairly important causes in emerging countries.

\section{Conclusion}

In conclusion, dropping out of school, defined as leaving the education system without having obtained a diploma at the end of secondary school, is indeed a socially unequal phenomenon. It mainly depends on the cultural capital of the parents. We believe that the main causes of dropping out of school at all levels of education in the two areas of residence are a high rate of absenteeism, learning 
difficulties, poor academic results, poor motivation of students for activities in school. The main challenges facing a pupil at high risk of dropping out are: family income up to subsistence level, poor parental education, lack of minimum conditions for home studies, poor economic conditions, socio-cultural inequalities, regional disparities. The Tunisian education system after the revolution (2011) recorded an increase in the number of students who drop out more frequently, which requires the identification and implementation, at national level, of alternative action systems to prevent and fight school dropout. In particular, systems are useful for the "health" of society. Such a possible alternative system must take into account issues such as support for families and the reduction of the main risk factors where the phenomenon of dropping out of school far exceeds the national average. It should also be considered that dropping out of school does not happen at the same level according to social groups and that, despite the transformations of the school systems, it remains more penalizing for young people from Tunisian working and rural backgrounds. But the process of dropping out of school is multidimensional and therefore complex. Young people who drop out of school all have different backgrounds, even if certain typologies can be advanced. Rather than normalizing the phenomenon, the typologies and risk factors identified should make it possible to prevent it. It is therefore complex but not impossible to remedy the dropout. If prevention is more effective than repair, it is also important to work on the social representations of dropping out of school.

\section{Conflicts of Interest}

The authors declare no conflicts of interest regarding the publication of this paper.

\section{References}

Battin-Pearson, S., Abbott, R. D., Newcomb, M. D., Karl, G., \& Hill, H. G. (2000). Prédicteurs du décrochagescolaire: un test de cinq théories. Journal of Educational Psychology, 92, 568-582. https://doi.org/10.1037/0022-0663.92.3.568

Bautier, É. (2006). Apprendre l'école, apprendre à l'école. Des risques de construction des inégalités dès la maternelle. Lyon: Chronique social.

Beaud, P. P. (2003). L'échantillonnage. In D. B. Gauthier (Ed.), Recherche sociale: De la problématique à la collecte des données (pp. 211-242). Sainte-Foy: Presses de l'Université du Québec.

Bernard, P.-Y. (2013). Le décrochage scolaire. Paris: PUF.

Bernard, P.-Y. (2017). Chapitre III. Question sociale, question scolaire? In P.-Y. Bernard (Ed.), Le décrochage scolaire (pp. 59-92). Presses Universitaires de France.

Blaya, C. (2010). Décrochages-L'école en difficulté, De Boeck. In C. Blaya, \& L. Fortin (Eds.), Les élèves français et québécois à risque de décrochage scolaire: Comparaison entre les facteurs de risque personnels, familiaux et scolaires (40/1). L'Orientation Scolaire et Professionnelle. https://doi.org/10.4000/osp.2988

Bloch, M. C., \& Gerde, B. (2004). Un autre regard sur les décrocheurs. Revue Internationale d'Éducation, 35, 89-97. https://doi.org/10.4000/ries.1738 
Boisonneault, J., Michaud, J., Côté, D., Tremblay, C., \& Allaire, G. (2007). L'abandon scolaire en Ontario français et perspectives d'avenir des jeunes. Éducation et francophonie, 15, 3-22.

Bosetti, L. (2004). Determinants of School Choice: Understanding How Parents Choose Elementary Schools in Alberta. Journal of Education Policy, 19, 387-405. https://doi.org/10.1080/0268093042000227465

Bulman, R. C. (2004). School Choice Stories: The Role of Culture. Sociologicial Inquiry, 74, 492-519. https://doi.org/10.1111/j.1475-682X.2004.00102.x

Bushnik, T. (2003). Composer des vies en transition: uneenquête narrative sur les expériences de ...édité par D. Jean Clandinin, Pam Steeves, Vera Caine. Éditions Emerald Group.

Bushnik, T., Barr-Telford, L., \& Buissière, P. (2002). À l'école secondaire ou non: Premiers résultats du deuxième cycle de l'Enquête auprès des jeunes en transition, 2002. Ottawa: Statistique Canada.

CEREQ (2005). Quand l'école est finie ... Premiers pas dans la vie active de la Génération 2001. London: Macmillan Press.

Chenu, F., \& Blondin, C. (Université de Liège) (2013). Décrochage et abandon scolaire précoce: Mise en perspective européenne de la situation en Fédération Wallonie-Bruxelles. Fédération Wallonie-Bruxelles.

Christenson, S. L., \& Thurlow, M. L. (2004). Décrocheursscolaires: considérations de prévention, interventions et défis. SAGE Journals, 13, 36-39. https://doi.org/10.1111/j.0963-7214.2004.01301010.x

Dalley, P., \& Saint-Onge, H. (2008). Choix scolaire des couples exogames au Yukon. Dans $\mathrm{P}$.

De Witte, K., Cabus, S., Thyssen, G., Groot, W., \& Maassen van den Brink, H. (2013). A Critical Review of the Literature on School Dropout. Educational Research Review, 10, 13-28. https://doi.org/10.1016/j.edurev.2013.05.002

Dubuc, C. (2003). Décrochage et abandon scolaires chez les jeunes de la Mauricie: Faits saillants. Rapport déposé à la Table régionale de l'éducation de la Mauricie.

English, R. (2009). Selling Education through "Culture": Responses to the Market by New, Non-Government Schools. The Australian Educational Researcher, 36, 89-104. https://doi.org/10.1007/BF03216894

Ensminger, M. E., \& Slusarcick, L. A. (1992). Parcoursversl'obtention du diplôme d'étudessecondairesou le décrochage: uneétudelongitudinaled'unecohorte de première année. Sociologie de l'éducation, 65, 95-113.

European Commission/EACEA/Eurydice/Cedefop (2014). Tackling Early Leaving from Education and Training in Europe: Strategies, Policies and Measures. Eurydice and Cedefop Report, Luxembourg: Publications Office of the European Union.

Favresse, D., \& Piette, D. (2004). Les jeunes en marge du système scolaire: Inscription dans une socialisation de l'exclusion. L'observatoire, 43, 87-91.

Fortin, L., \& Picard, Y. (1999). Les élèves à risque de décrochage scolaire: Facteurs discriminants entre décrocheurs et persévérants. Revue des sciences de l'éducation, 25, 10.7202/032005ar. https://doi.org/10.7202/032005ar

Fortin, L., Marcotte, D., Potvin, P., Royer, É., \& Joly, J. (2006). Typology of Students at Risk of Dropping Out of School: Description by Personal, Family and School Factors. European Journal of Psychology of Education, 21, 363-383. https://doi.org/10.1007/BF03173508

Galand, B., \& Hospel, V. (2015). Factors Associated with the Risk of School Dropout: 
Toward an Integrative Approach. https://doi.org/10.4000/osp.4604

Gingras, G. (1995). Prévenir le décrochage scolaire. Montréal: Lidec.

Gyonos, E. (2011). School Dropout-Causes and Effects. Theoretical and Applied Economics, 18,564 .

Herin, R. (1990). Disparities in Schooling in France. One Indicator: The Baccalaureate Graduation Rate. Social Geography, No. 9, 151-172.

Herin, R. (1993). School Education: The Geographic Dimensions of Inequality of Opportunity. Space, Populations, Societies, 2, 343-354.

https://doi.org/10.3406/espos.1993.1593

Janosz, M. (2000). L'abandon scolaire chez les adolescents: Perspective nordaméricaine. VEI Enjeux, 122, 105-114.

Janosz, M., LeBlanc, M., \& Boulerice, B. (1997). Démêler le poids des prédicteurs du décrochagescolaire: un test sur deuxéchantillonslongitudinaux. Journal of Youth and Adolescence, 26, 733-762. https://doi.org/10.1023/A:1022300826371

Jimerson, S. R., Egeland, B., Sroufe, L. A., \& Carlson, B. (2000). Uneétudelongitudinale prospective des décrocheurs du secondaire: examen de plusieursprédicteurs tout au long du développement. Journal of School Psychology, 38, 525-549.

https://doi.org/10.1016/S0022-4405(00)00051-0

Kovač-Cerović, T., Pavlović Babić, D., Jokić, T., Jovanović, O., \& Jovanović, V. (2016). First Comprehensive Monitoring of Inclusive Education in Serbia: Selected Findings. Dans le livre: Challenges and Perspectives of Inclusive Education, éditeur: Institute for Educational Research, Belgrade, Serbie; Université socio-pédagogiqued'État de Volgograd, Volgograd, Russie; Faculté de formation des enseignants, Belgrade, Serbie, éditeurs: NikoletaGutvajn, MiljaVujačić (pp. 15-30).

Looker, D., \& Thiessen, V. (2008). Le système de la seconde chance: Résultats des trois cycles de l'Enquête auprès des jeunes en transition. Ottawa: Ressources humaines et développement social Canada.

MEN DEP (1993a). Geography of the School (p. 84). Paris.

MEN DEP (1993b). L'état de l'école. Ministère de l'Education Nationale en France.

Mihalache, F. (2011). School Dropout in Eight Urban Schools in the "Quality of Life Magazine", No. 3.

Potvin, P, \& Pinard, R. (2010). L'alliance possible entre deuxapprochesenprévention du décrochagescolaire au. Québec: l'apporhcescolaireetl'approche périscolaire. Communication présentée au 16e Congrès de l'AMSE. Monterrey.

Potvin, P. (2005). La relation maître-élève et l'élève en difficulté. In D. L. DeBlois (Ed.), La réussite scolaire: Comprendre et mieux intervenir (pp. 109-118). Québec: Presses de l’Université Laval.

Potvin, P., Deslandes, R., Beaulieu, P., Marcotte D., Fortin, L., Royer, É., \& Leclerc, D. (1999). Risque d'abandon scolaire, style parental et participation parentale au suivi scolaire. Revue canadienne de l'éducation, 2, 441-453. https://doi.org/10.2307/1585897

Potvin, P., Fortin, L., \& Girard, F. (2006). Évaluation des quatre types d'élèvesàrisque de décrochagescolaire. Présentation au colloque des psychoéducateursen milieu scolaire. UQTR Dépistage d'élèvesàrisque de décrochage.

Potvin, P., Fortin, L., Marcotte, D., Royer, E, \& Deslandes, R. (2004). Guide de prévention $d u$ décrochage scolaire. Editions, Centre de transfert pour la réussiteéducative du Québec (CTREQ).

Rousseau, N., Tétreault, K., \& Vézina, C. (2006). Portrait de trois cohortes d'élèves de la 
Mauricie: Rapport final. Observatoire de l'insertion sociale et professionnelle des jeunes de la Mauricie, Québec: Université du Québec à Trois-Rivières.

Rumberger, R. (1995). Décrochagescolaire: uneanalyseàplusieursniveaux des élèveset des écoles. Journal américain de recherche pédagogique, 32.

Rumberger, R. (2011). Dropping Out: Why Students Drop Out of High School and What Can Be Done about It. Cambridge, MA: Harvard University Press. https://doi.org/10.4159/harvard.9780674063167

Savoie-Zajc, L. (2000). La recherche qualitative/interprétative. In D. T. Karsenti, \& L. Savoie-Zajc (Eds.), Introduction à la recherche en éducation (pp. 171-198). Sherbrooke: Éditions du CRP.

Stearns, E., Moller, S., Blau, J., \& Potochnick, S. (2007). Resterenarrière etabandonner: la relation entre la persévérancescolaire et le décrochagescolaire. Sociologie de l'éducation, 80, 210-240. https://doi.org/10.1177/003804070708000302

Thibert, R. (2013). Le décrochage scolaire: Diversité des approches, diversité des dispositifs. Dossier d'actualité, veille et analyses, No. 84, 12.

Truong, N. (2006). Comment leur donner confiance? Le monde de l'Éducation, 350, 2038.

Tunisian Ministry of Education (2016). Le système éducatiftunisien: enjeuxet défis. Edition République Tunisienne, Direction générale des études, de la planificationet des systèmesd'information, Instituttunisien de la compétitivité et des étudesquantitatives.

Tunisian Ministry of Education (2017). Statistiquesscolaires. Edition République Tunisienne, Direction générale des études, de la planificationet des systèmesd' information. http://www.education.gouv.tn/ 